\title{
Training Needs Assessment for Leaders in Nursing Based on Comparison of Competency Models
}

\author{
Andreja Kvas', Janko Seljak ${ }^{2}$, Janez Stare ${ }^{2}$ \\ ${ }^{1}$ University of Ljubljana, Faculty of Health Sciences, Zdravstvena pot 5, 1000 Ljubljana, Slovenia; andreja.kvas@zf.uni-lj.si \\ ${ }^{2}$ University of Ljubljana, Faculty of Administration, Gosarjeva ulica 5, 1000 Ljubljana, Slovenia; \\ janko.seljak@kabelnet.net, janez.stare@fu.uni-lj.si
}

Background and Purpose: The main purpose behind the formation of leadership competency models must be the improvement of leadership. A competency model should serve as one of the tools for selecting the most suitable leaders, appraising their work, assessing training needs and preparing programmes of functional and formal education. The objective of this research is to assess the training needs of leaders in health care. A comparison of leadership competency models between different professional groups should serve as one of the tools with which to assess the training needs of various levels of leaders.

Design/Methodology/Approach: A descriptive study using a survey design was conducted on 141 nurse leaders in Slovenia. Respondents indicated to what extent each of 95 different behaviours was characteristic of a person at their leadership level.

Results: The most important competence dimensions (groups of behaviours) for leaders in health care are (1) at the first - top leadership level: strategic thinking, openness to change and responsibility; (2) for leaders at the second - middle leadership level: relations with co-workers, animation, resistance to stress; and (3) for leaders at the third leadership level: realisation skills, execution of procedures, communication. Training needs assessments were done for three leadership levels in nursing care.

Conclusions: The greatest need for training of nurse leaders can be observed at the third leadership level. Special training programmes should be organised in the competency areas of realisation skills, execution of procedures, communication, education and ethics.

Keywords: Competence; nursing care; leadership; public administration; Slovenia.

\section{Introduction}

Changes in the sphere of health care for the general population that are the consequence of different contemporary factors (demographical changes, technological development in the field of medicine, consumer behavioural patterns and so forth) are continuously demanding new approaches to operation and organisation in the public sector and in public health care. Many of those changes are driven by the demand for greater efficiency, effectiveness and excellence in the provision of public and private health care services.
Within the health care systems of the majority of countries, the public and private sectors exist in parallel. Ratios differ from country to country, but the health care systems in the majority of European countries are designed in such a way that the largest part is still within the public sector (WHO, 2013). The use of excellence management tools and systems was for a long time limited to the private sector. Such tools only began to appear in the public sector in Europe in the early 1990s, as part of efforts for modernisation, better public management, increased measurement of

Received: $3^{\text {rd }}$ October 2013; revised: $20^{\text {th }}$ November 2013; accepted: $4^{\text {th }}$ January 2014 
efficiency and performance and a stronger "customer" focus (Engel, 2002).

These changes are designed to cause a "post-bureaucratic paradigm" characterised by a shift from bureaucratic behaviour to enterprise behaviour (Brooks, 2003). One of the approaches designed to ease this transition is the use of competency models. The main task in the development of competency models is to establish a framework within which competencies can be defined and, within the context of competency profiles, the level of competencies that leaders need in order to do their job successfully. Such a framework should serve as one of the tools with which to select the most suitable candidates for leadership positions, appraise the work of leaders, assess training needs for various levels of leaders and prepare programmes of functional and formal education (Boyatzis, 2008; Mühlbacher et al., 2013; Sarkar, 2013).

Leadership is one of the most important factors affecting the performance and excellence of an organisation (Šparl et al., 2013). The importance of leadership is underlined in various excellence models, e.g. EFQM (European Foundation for Quality Management) (EFQM, 2013) and a special form thereof designed for use in the public sector, the CAF (Common Assessment Framework). In both excellence models, leadership stands out as an important criterion in the assessment of an organisation. By leadership they mean "leading with vision, inspiration and integrity excellent organisations have leaders who shape the future and make it happen, acting as role models for its values and ethics" (EIPA, 2012; EFQM, 2013).

Leadership has without a doubt been one of the most researched areas in the social sciences field for more than 2000 years (Northouse, 2007; Dimovski et al., 2012). It has been studied in the context of various disciplines, and therefore there are probably as many definitions of leadership as there are writers who have attempted to define it (OECD, 2001). The commonest and simplest definition is that "leadership is a process whereby an individual influences a group of individuals to achieve a common goal" (Northouse, 2007). Leadership standards, characteristics and competency models today form the basis for the development of leadership/management and reviewing progress and procedures within the majority of large organisations (Bolden, 2004).

Competencies are those values, intentions, personal characteristics, abilities, skills, behaviours, knowledge, etc. on the basis of which the individual can develop models of (organisational) behaviour that enable them to work effectively and efficiently. Competencies can only be defined on the basis of observation of the behaviour of the individual (actions in real situations). A system of key competencies formulated on the basis of a study of key indicators of effective leadership behaviour is called a competency model of leadership. When we define normative values of individual (required) competencies within the context of a competency model, we get a competency profile (Stare, 2009; Stare \& Seljak, 2013).

The main purpose behind the formation of leadership competency models must be the improvement of leadership, which will have a positive influence on the efficiency and effectiveness of public administration and the quality of services it offers. The requirements of the job in public administration affect the activity and behaviour of staff. Specific principles of work in public administration are characteristic of all its subsystems, and therefore the behaviours of the leaders managing these subsystems are also similar. For leaders in public administration, a specific part of the environment in which they must lead is the same for all of them (public administration, predominantly non-profit work, problems with motivating staff, etc.) - something we can try and illustrate with generic competencies - while another part of the environment varies from profession to profession - role-specific competencies (in other words additional competencies for leaders in state administration, education, health care, etc.). It is therefore important for public administration to have a developed leadership competency model that can be applied (taking into account the specific characteristics of individual fields) in various fields of public administration. In the field of competency models, models already exist for larger groups of leaders (leaders in state administration, leaders in public health care, change leaders, etc.), which indicates one of the possible directions for greater integration (Cook at al., 2008, Stefl \& Bontempo, 2008, Marulc \& Devetak, 2013).

In our research, we formulated a competency model of leadership in health care and compared it to the competency model of leadership in state administration (Stare, 2009). In 2011, there were 18,624 nurses employed in the health care sector in Slovenia, of whom between 1,650 and 2,250 were leaders (Institute of Public Health, 2010; Kvas 2013). We compare this group with the group of employees in the civilian part of the state administration in Slovenia, in which there were 15,984 employees in 2011, of whom between 1,900 and 2,300 were leaders (Stare \& Seljak, 2013; Kvas, 2013).

The competency model of leadership in state administration was presented in Slovenia in 2007. In the research, on which the competency model was based, 147 leaders in state administration participated. The share of women participating in the survey was $40.9 \%$. A total of $77.5 \%$ of the respondents had a college or higher education. A total of $24.5 \%$ of the respondents were below 40 years of age. The model is set up for state administration and emphasises the competencies that are characteristic of leadership in administrative units, ministries, directorates and government agencies (Stare, 2009; Stare \& Seljak, 2013).

In most developed countries, health care systems are a part of the public sector, both in terms of providers and in terms of funding; however, the private sector is gaining significance in the field of health care. Nevertheless, we 
can assume that in the future the public sector will remain dominant in the field of health care due to the importance of public health, particularly in the countries of the European Union. Consequently, the majority of nurses will be influenced by factors that are influencing other public employees. The competency model of leadership in nursing is composed from the part that is the same for all leaders working in public administration and from the part that is specific for nurse leaders. This would halt the excessive growth in the number of different competency models while preserving the diversity required by the specificity of the individual group. Another fundamental advantage of a model of this type is that it is possible to compare the level of competencies and competency profiles of leaders in different groups and in this way obtain additional information both about the difficulties of leadership in individual fields and an assessment of leadership training needs.

The basis for the nursing profession and nurses' knowledge is a good educational system that must be supplemented with continuing education and training (CET) following graduation and should be provided by professional associations and health care organisations (Yoder-Wise \& Brigher, 2007). Nurses must accept learning and training as an integral part of their profession. Nurse CET, nurse experience and nurse professional development play a significant role in the evaluation of nurse competence (Kvas and Seljak, 2013). This is particularly true of nurse leaders, who bear the responsibility for the good leadership of this professional group. In the course of her career, each nurse assumes various leadership roles. CET comprising leadership is therefore a key part of a nurse's career development and must begin immediately after graduation and continue systematically throughout a nurse's career (Yoder-Wise \& Brigher, 2007; Kvas \& Seljak, 2013).

The content, scope and forms of CET are determined by professional associations (ICN, 2009). Professional learning programmes in Slovenia are approved by the Nurses and Midwives Association of Slovenia (NMA). In addition to the NMA, CET programmes are also organised by health care organisations, civil associations (e.g. patients' associations) and providers of various contents related to nurses' work. Due to the variety of organisers, an accurate registry of the types and scopes of nurse CET in Slovenia does not exist.

However, health care organisations also play an important role in CET, for their task is to enable and encourage it. The correct selection, education and training of leaders who are capable of appropriately motivating their co-workers to achieve targets are key elements of the excellence, efficiency and effectiveness of every organisation. One of the key roles of leaders in health care organisations is to create a learning-friendly environment and to present knowledge as a virtue. Nurse leaders must set an example and possess knowledge of leadership, education and management (Kvas \& Seljak, 2013).
The main objective of this paper is to assess training needs of leaders in nursing care. We were interested in (research questions):

- What are the differences between the competency profiles of leaders in state administration and nursing care?

- What are the differences between the competency profiles of the different levels of leaders in nursing care?

- What are the differences between the level of generic and role-specific competencies in nursing care?

On the basis of comparison of competency models, we assessed the training needs of leaders in nursing care. The competency-based approach could help identify what knowledge, skills, attitudes and behaviours are necessary for leaders in nursing care to successfully perform their roles in their organisation.

\section{Methods}

\subsection{Research design}

Slovenia belongs to the group of countries with a predominantly public health care system (WHO, 2013). Slovenia has 24 public hospitals (general hospitals, specialist hospitals and two university medical centres) and 64 public health centres, which in 2009 employed $84 \%$ of all graduate nurses, midwives and nurse assistants in Slovenia (Institute of Public Health, 2010). It is therefore also logical to use the state administration competency model for leaders in nursing care, although the model needs to be expanded to include the specific competencies characteristic of this field of work.

The competency model of leadership in nursing care is composed from the part that is the same for all leaders working in public administration and from the part that is specific for nurse leaders. The "Competency model for leaders in state administration" (Stare 2009; Kvas, 2013) covers 77 behaviours or actions that are divided into seven groups of competencies. We will call this group of competencies "Generic competencies". "Generic competencies" are also assumed to be characteristic of nursing care leaders, at least those working in the public sector.

On the basis of an analysis of leadership theory and competency models (Biesma et al., 2008; Delamare \& Winterton, 2005) and secondary analysis of data from the research project carried out in Slovenia on a representative sample of nurses (Kvas, 2013), 18 nursing care specific behaviours were added to generic competencies. Three groups of competences characteristic of those in leadership positions in nursing were developed on their basis:

- Seven behaviours indicating ethical/unethical behaviour by nurse leaders were selected (ethics in nursing care). 
Table 1. Generic competencies and nursing care specific competencies for nurse leaders

\begin{tabular}{|c|c|c|}
\hline Competency & Characteristics & No of items \\
\hline \multicolumn{2}{|c|}{ Generic leadership competencies } & 77 \\
\hline Flexibility at work & $\begin{array}{l}\text { Rapid adaptation and orientation in a concrete problem situation. Involves having } \\
\text { a good command of the area of work, effective use of resources currently available } \\
\text { for high-quality provision of services and keeping control of the situation (e.g. } \\
\text { resistance to stress). }\end{array}$ & 13 \\
\hline Creativity & Ingenuity and adaptability in a new situation, going beyond the standard approach. & 15 \\
\hline Leadership & $\begin{array}{l}\text { The process whereby a leader influences people on the basis of his/her own com- } \\
\text { petencies, through a characteristic approach, to (mutually) achieve (agreed) goals. }\end{array}$ & 14 \\
\hline $\begin{array}{l}\text { Organisational cli- } \\
\text { mate }\end{array}$ & $\begin{array}{l}\text { Combined factors influencing the well-being, motivation and satisfaction of co- } \\
\text { workers and customers (patients). }\end{array}$ & 14 \\
\hline Organisation & $\begin{array}{l}\text { Organisation of efficient work on the basis of knowledge of the organisation and } \\
\text { functioning of public administration (health care system). Rapid but careful deci- } \\
\text { sion-making and efficient management of all available resources. }\end{array}$ & 8 \\
\hline $\begin{array}{l}\text { Networking and } \\
\text { influencing }\end{array}$ & $\begin{array}{l}\text { Establishment of connections with people and networks that have an influence } \\
\text { on key decisions and drawing information on this basis. Ability to handle public } \\
\text { relations and media relations and to speak in front of an audience. Being generally } \\
\text { well-informed and keeping up to date with developments. }\end{array}$ & 7 \\
\hline Realisation skills & $\begin{array}{l}\text { Focus on achievement of goals. Ability to transform strategies into clear, reason- } \\
\text { able (attainable) and operational goals. Persistence in overcoming difficulties and } \\
\text { the ability to put own ideas into effect. }\end{array}$ & 6 \\
\hline \multicolumn{2}{|c|}{ Nursing care specific competencies } & 18 \\
\hline Ethics of conduct & $\begin{array}{l}\text { Priority is not given to relatives, acquaintances and colleagues, violations of nurs- } \\
\text { ing regulations are reported, patient privacy is protected, patient is informed about } \\
\text { nursing activities. }\end{array}$ & 7 \\
\hline $\begin{array}{l}\text { Interprofessional } \\
\text { relationships }\end{array}$ & $\begin{array}{l}\text { Cooperation and communication with doctors on equal footing, differentiation } \\
\text { between nursing and medicine, knowledge of nursing and its role in the health care } \\
\text { system, taking responsibility for the sphere of nursing in the health care team. }\end{array}$ & 5 \\
\hline $\begin{array}{l}\text { Positive attitude } \\
\text { towards knowledge } \\
\text { and education }\end{array}$ & $\begin{array}{l}\text { Knowledge of work in the management and economics/business fields, ability to } \\
\text { communicate in foreign languages, knowledge of work with new technologies, } \\
\text { knowledge of quality standards, encouraging education of co-workers. }\end{array}$ & 6 \\
\hline All competencies & & 95 \\
\hline
\end{tabular}

- Five behaviours were selected indicating a correct understanding of the position of nurses in the health care system and their relationship with doctors (interprofessional relationships).

- Six behaviours indicating the attitude of nurse leaders to the education of their subordinates and their own education were selected (positive attitude of leaders towards knowledge and education).

The questionnaire contained a total of 95 items organised into ten groups or competences (Table 1). Respondents indicated to what extent each of 95 different behaviours or actions was characteristic of a person at their leadership level. They used a five-point scale, from 1: com- pletely uncharacteristic behaviour, to 5: decisive behaviour. Respondents did not describe the actual situation (how they behave or should behave) but instead what behaviour should be characteristic of a person at their leadership level.

\subsection{Sample and methods of data collection}

The survey was carried out at the Congress of Nursing and Midwifery of Slovenia in May 2009. The congress is a special form of expert work of the Nurses and Midwives Association of Slovenia, where expert recommendations for the development of the nursing and midwifery profession are presented. A total of 250 questionnaires were distributed 
Table 2. Demographic data on the sample of nurse leaders.

\begin{tabular}{llcc}
\hline & & Number & \% \\
\hline Gender & Female & 134 & 95.0 \\
& Male & 7 & 5.0 \\
\hline Age & 21 to 30 & 10 & 7.1 \\
(years) & 31 to 40 & 45 & 31.9 \\
& 41 to 50 & 62 & 44.0 \\
& 51 to 60 & 21 & 14.9 \\
& N/A & 3.1 \\
\hline Education & Three-year higher education & 3 & 14.2 \\
& Professional college & 20 & 61.7 \\
& Bachelor's degree or higher & 87 & 23.4 \\
& N/A & 33 & 0.7 \\
\hline & First level & 1 & 29.8 \\
& Second level & 42 & 40.4 \\
& Third level & 57 & 29.1 \\
Leadership level & N/A & 41 & 0.7 \\
\hline Total & & 1 & $\mathbf{1 0 0 . 0}$ \\
\hline
\end{tabular}

a First leadership level: head nurses of hospitals/clinics, assistant directors of nursing.

Second leadership level: Leaders of wards, clinical departments, operational blocks, hospital units, outpatients' clinic groups, hospital centres.

Third leadership level: team leaders, senior nurses, small department heads.

$b_{N / A}$ : no answer.

to the participants in the Congress, with 141 nurse leaders (56.4\%) returning completed questionnaires (Table 2).

\subsection{Statistical analysis}

The data was analysed using SPSS 19.0. Descriptive statistics were used to describe the sample. Based on the results for individual behaviours, a simple arithmetic mean was used to calculate values for 10 competencies. Internal consistency was examined using the Cronbach's alpha. Factor Analysis was used to determine the construct validity (Rattray \& Jones, 2007). In the factor analysis, principal component analysis with varimax rotations was used to examine which factors of the scale comprised coherent groups of items (Blaikie, 2003). The Kaiser-Meyer-Olkin (KMO) test and Bartlett's test of sphericity were applied to measure sampling adequacy (Munro, 2005; Lin et al., 2010). Relationships between variables were analysed using oneway analysis of variance (ANOVA). A significance level of alpha $=0.05$ was used for all statistical tests.
We compared the competency model for nurse leaders with the competency model for the group of leaders in the civilian part of the state administration. Due to different variability within individual groups of leaders, we standardised the values. Relations between norms are formulated on the basis of the relations between the minimum and maximum values. For competency model for nurse leader and competency model for leaders in state administration, we obtained a comparative evaluation scale - the values of the norms range between 3.2 and 5.0 for both groups. We defined 3.2 as the lowest possible norm (55\% of the value of the highest score) and 5 as the highest norm $(100 \%$ of the value of the score) (Kvas, 2013). The calculated values can be directly compared between the two models.

\subsection{Ethical consideration}

The study was approved by the Honorary Court of Arbitration of the Nurses and Midwives Association of Slovenia. Participants were assured that there was no risk 
from participating in the study and that their responses would be treated confidentially.

\section{Results}

The reliability of the measuring instrument was assessed for each of the ten competencies. Cronbach's alpha was between 0.76 and 0.93 . The value indicated a high level of reliability of the measuring instrument.

Factor Analysis was applied to determine the construct validity for each of the ten competencies. The KMO measure of sampling adequacy was between 0.72 and 0.94 and indicated that factor analysis was appropriate. Bartlett's test was significant (p-value less than 0.005). The Principal Component Analysis (PCA) method was applied to the

Table 3. Norms for the competency profiles for three leadership levels in nursing care and in state administration

\begin{tabular}{|c|c|c|c|c|c|c|}
\hline & \multicolumn{3}{|c|}{ Leaders in nursing care ${ }^{a}$} & \multicolumn{3}{|c|}{ Leaders in state administration $b$} \\
\hline & \multicolumn{3}{|c|}{ Leadership level } & \multicolumn{3}{|c|}{ Leadership level } \\
\hline & First & Second & Third & First & Second & Third \\
\hline All competencies $(\mathrm{M} \pm \mathrm{SD})$ & $4.56 \pm 0.22$ & $4.62 \pm 0.19$ & $3.55 \pm 0.16$ & & & \\
\hline Generic competencies $(\mathrm{M} \pm \mathrm{SD})$ & $4.70 \pm 0.10$ & $4.64 \pm 0.18$ & $3.50 \pm 0.17$ & $4.55 \pm 0.25$ & $3.96 \pm 0.27$ & $3.67 \pm 0.31$ \\
\hline Flexibility at work & 4.6 & 4.7 & 3.6 & 4.3 & 3.9 & 3.8 \\
\hline - Execution of procedures & 4.5 & 4.6 & 3.8 & 4.3 & 3.9 & 3.9 \\
\hline - Communication & 4.6 & 4.5 & 3.8 & 4.6 & 3.8 & 3.7 \\
\hline - Resistance to stress & 4.6 & 4.8 & 3.4 & 4.1 & 3.9 & 3.9 \\
\hline Creativity & 4.9 & 4.5 & 3.5 & 4.7 & 4.0 & 3.6 \\
\hline - Strategic thinking & 4.9 & 4.3 & 3.4 & 4.8 & 4.3 & 3.3 \\
\hline - Openness to change & 4.9 & 4.6 & 3.5 & 4.5 & 4.1 & 3.7 \\
\hline - Use of effective methods & 4.6 & 4.6 & 3.6 & 4.9 & 3.7 & 3.6 \\
\hline Leadership & 4.8 & 4.8 & 3.5 & 4.2 & 4.0 & 3.8 \\
\hline - Responsibility & 4.8 & 4.7 & 3.7 & 4.1 & 3.8 & 4.1 \\
\hline - Animation & 4.7 & 4.9 & 3.4 & 4.3 & 4.3 & 3.6 \\
\hline Organisational climate & 4.6 & 5.0 & 3.4 & 4.5 & 3.7 & 4.0 \\
\hline - Relations with co-workers & 4.6 & 5.0 & 3.5 & 4.5 & 3.6 & 4.1 \\
\hline - Dealing with customers & 4.4 & 4.8 & 3.5 & 4.5 & 3.7 & 3.9 \\
\hline Organisation & 4.7 & 4.5 & 3.5 & 4.5 & 3.5 & 4.1 \\
\hline Networking and influencing & 4.6 & 4.5 & 3.2 & 4.7 & 4.3 & 3.3 \\
\hline Realisation skills & 4.7 & 4.5 & 3.8 & 5.0 & 4.3 & 3.2 \\
\hline $\begin{array}{l}\text { Nursing care specific competencies } \\
(\mathrm{M} \pm \mathrm{SD})\end{array}$ & $4.23 \pm 0.26$ & $4.57 \pm 0.12$ & $3.67 \pm 0.04$ & & & \\
\hline Ethics & 3.9 & 4.6 & 3.7 & & & \\
\hline Interprofessional relationship & 4.4 & 4.7 & 3.6 & & & \\
\hline $\begin{array}{l}\text { Positive attitude towards knowledge and } \\
\text { education }\end{array}$ & 4.4 & 4.4 & 3.7 & & & \\
\hline Comparison of generic and role-specific c & mpetencies & & & & & \\
\hline F-test & 14.8 & 0.3 & 2.3 & & & \\
\hline Sig. & 0.005 & 0.574 & 0.171 & & & \\
\hline
\end{tabular}

Source: ${ }^{a}$ our research; ${ }^{b}$ Stare, 2009; Kvas et al., 2013. 
extraction of components. According to Kaiser criterion, only the factors that have eigenvalues greater than one are retained. Between one and three factors were extracted from the five to 15 leadership behaviours (items), which accounted for $51.7 \%$ to $72.7 \%$ of variability. Varimax rotation was applied in order to optimise the loading factor of each item on the extracted components. All of the factor loadings were greater than 0.40 (between 0.44 and 0.88 ). This indicates good construct validity.

The values of the competency norms for nurse leaders and leaders in the civilian part of the state administration are shown in Table 3. The required levels of competencies in the case of the highest nurse leaders were 4.7 on average, which was slightly higher than for leaders in state administration (4.55). According to the scores of the respondents, the most important competencies for leaders at the first leadership level in nursing care are from the following areas:

- Creativity (4.9). In nursing care, leaders apparently think more strategically and are more open to change than those in state administration, while use of effective methods is considerably lower than that of leaders in state administration.

- Leadership (4.8). Within this competency, the competence dimension of responsibility was 0.6 higher and the competency dimension of animation 0.4 higher than in the case of leaders in state administration.

- Leaders in nursing care are also said to have significantly higher norms than leaders in state administration in the field of flexibility at work, particularly with regard to the competency dimension of resistance to stress $(0.5)$.

The average of the seven competencies for second-level leaders in state administration is 3.96, while for leaders in nursing care it is 4.64 . The norms for the second leadership level in nursing care are significantly higher.

In nursing care, the most important competencies for leaders at the second level are from the following areas:

- organisational climate, in particular the competency dimension of relations with co-workers (5);

- leadership, in particular the competency dimension of animation (4.9);

- resistance to stress (4.7) and

- interprofessional relationships (4.7).

A comparison of the third leadership level shows that this is the area where norms in state administration are higher (average value 3.67) than norms in nursing care (3.50).

The analysis of differences between the leadership levels in nursing care was carried out using the basic values and clearly shows that norms differ among the three leadership levels (ANOVA). Statistically significant differences between groups appeared in all observed fields except education. We can see, however, from the arithmetic means that a deviation from the other two groups was particularly marked in the case of nurses at the third leadership level. We therefore verified the differences between each pair of leadership levels. The test showed (Post hoc test - Tukey's Honestly Significant Differences test) that no statistically significant differences can be seen between the first and second leadership levels in nursing care in any of the observed fields. Leaders at the third leadership level, however, show lower norms in the majority of competencies than the other two groups of leaders $(\mathrm{p}<0.05)$. The lowest norms at the third leadership level are in the field of networking and influencing (3.2), while the highest are in the areas of realisation skills (3.8) and flexibility at work, in particular the competence dimensions of execution of procedures and communication (3.8).

Finally, we verified whether the level of norms for generic competencies differs from the three role-specific competencies for leadership in nursing care (Table 3). The average for the first seven generic competencies was statistically significantly higher among leaders at the first leadership level (4.70) than for the last three role-specific competencies (4.23) (ANOVA, F-test $=14.8, \mathrm{p}<0.005$ ). Among leaders at the second level of leadership, there were almost no differences (ANOVA, F-test $=0.3, \mathrm{p}=0.574$ ). Among the third group, generic competencies of leaders in public administration are less important than competencies that are supposed to be characteristic of leaders in nursing care (although not statistically significant, ANOVA, F-test $=2.3$, $\mathrm{p}=0.171)$.

On the basis of competence model, we can assess training needs for nurse leaders. The assessment is even better if we can compare it with the competence models for leaders in other professions. A comparison of models formulated in this way enables easier identification of the training needs of individual groups of leaders. On the basis of a comparison of competency profiles, we can evaluate the areas in which training needs are greatest for an individual professional group. For nurse leaders, we have formulated a training needs assessment (Table 4):

- with regard to the level of norms in the leadership competency model in nursing care, and

- with regard to differences between norms in the leadership competency model in nursing care and in state administration.

\section{Discussion}

Leaders at the first leadership level need additional training in the competency areas of resistance to stress, strategic thinking, openness to change, positive attitude towards education and interprofessional relationships. They have to perform tasks that require a high level of strategic thinking and openness to change. They have to bear all the responsibility for their decisions and be able to cope with stressful situations. The most important role-specific competencies for the 
Table 4. Training needs assessment for nurse leaders ${ }^{a}$

\begin{tabular}{|c|c|c|c|}
\hline & \multicolumn{3}{|c|}{ Leadership level } \\
\hline & First & Second & Third \\
\hline \multicolumn{4}{|l|}{ Flexibility at work } \\
\hline - Execution of procedures & & & $*$ \\
\hline - Communication & & & $*$ \\
\hline - Resistance to stress & $*$ & & \\
\hline \multicolumn{4}{|l|}{ Creativity } \\
\hline - Strategic thinking & $*$ & & \\
\hline - Openness to change & $*$ & & \\
\hline \multicolumn{4}{|l|}{ - Use of effective methods } \\
\hline \multicolumn{4}{|l|}{ Leadership } \\
\hline - Responsibility & $*$ & & \\
\hline - Animation & & $*$ & \\
\hline \multicolumn{4}{|l|}{ Organisational climate } \\
\hline - Relations with co-workers & & * & \\
\hline - Dealing with customers & & * & \\
\hline \multicolumn{4}{|l|}{ Organisation } \\
\hline \multicolumn{4}{|l|}{ Networking and influencing } \\
\hline Realisation skills & & & $*$ \\
\hline Ethics & & & $*$ \\
\hline Interprofessional relationship & $*$ & * & \\
\hline Positive attitude towards knowledge and education & $*$ & & $*$ \\
\hline
\end{tabular}

Note: ${ }^{a}$ areas in which additional training is necessary.

first leadership level are a positive attitude towards education and good interprofessional relationships (Fukurawa \& Cunha, 2011; Spicer et al., 2011). The results of our research show that the similarity of competency norms in state administration and nursing care is greatest at this leadership level. Among this group of leaders, the "classic" competencies of leaders in public administration predominate, while there are fewer characteristics of leaders in nursing care. First level nurse leaders represent a nursing profession in the top management of health care and other organisations. Communications of first level nurse leaders with other leaders are frequent both inside and outside of the organisation.

Leaders at the second leadership level need additional training in the competency areas of animation, relations with co-workers, dealing with customers and interprofessional relationships. They typically have the most relationships with different groups of people - they have an intermediary role between the first and third leadership levels, they coordinate activities with other professional groups in health care and they are also responsible to a large extent for com- munication with patients. Leaders at this level lead relatively large groups of co-workers, although they only participate to a small extent in the actual provision of nursing (Lin et al., 2005; McCarthy and Fitzpatrick, 2009).

Leaders at the third leadership level need additional training in the competency areas of realisation skills, execution of procedures, communication, ethics and positive attitude towards education. They are strongly involved in the actual process of providing nursing care. This points to the fact that leaders at the lowest leadership level are torn between the actual provision of nursing care and leadership and are not prepared to fully accept the role of leaders (Twedell and Jackson Gray, 2007). This leadership level is in fact a link between other nurses and leaders and plays an important role at the start of the career of every nurse (communication, positive attitude towards education and ethics). Nurse leaders even at the lowest leadership level should be aware of the importance of their role as leaders and should be building up their professional identity, which should already have formed during their time as students. 
Some limitations in the research should be pointed out. First, the relatively low response rate $(56.4 \%)$. Second, the discussed findings and implications were obtained from two studies with two different samples and in two different years; generalising the results of comparison should be done with caution. Third, the competency approach is a relatively new concept of leadership. Although it is widely accepted, the opinion exists that the competency approach is not a good way of selecting, measuring and developing leaders and more consideration should be placed on reflection, discussion and experience (Bolden \& Gosling, 2006) and on the practical side of leadership (Caroll et al., 2009).

\section{Conclusion}

In our research, training needs assessments were done for three leadership levels in nursing care on the basis of differences between competency profiles of leaders in state administration and nursing care, competency profiles of the different levels of leaders in nursing care and level of generic and role-specific competencies in nursing care. Nurses are a professional group bound to lifelong education due to the characteristics of their profession as well as legal requirements. It is an essential task of both professional associations and the educational system for health care to equip nurses with leadership knowledge, for only those professional groups with adequate leadership can be successful

Professional associations that have the necessary infrastructure and conditions should prepare appropriate CET programmes. The training of leaders is particularly important for they are a part of the leadership structure in health care organisations and have the ability to influence and change the organisational culture. Emphasis should be placed on interdisciplinary programmes that would ensure the training of independent and broad-minded nurses. CET programmes should be organised for each leadership level in nursing. The greatest need for training can be observed at the third leadership level. Special training programmes should be organised in the competency areas of realisation skills, execution of procedures, communication, education and ethics.

A long-term solution would be to introduce additional courses on leadership in higher education programmes for nurses. The level required for competencies at the lowest leadership levels in health care needs to be significantly increased, since this would ease the transition between different leadership levels in health care and increase the number of potential candidates for middle and higher leadership positions.

\section{References}

Biesma, G. R., Pavlova, M., Vaatsra, R., Van Merode, G. G., Czabanowska, K., Smith, T., et al. (2008). Generic Versus
Specific Competencies of Entry-Level Public Health Graduates: Employers' Perceptions in Poland, the UK, and the Netherlands. Advances in Health Sciences Education, 13(3), 325-343, http://dx.doi.org/10.1007/s10459-006-9044-0

Blaikie, N. (2003). Analyzing Quantitative Data: From Description to Explanation. London: SAGE Publications.

Bolden, R. (2004). What is Leadership? Exeter: University of Exeter.

Bolden, R., \& Gosling, J. (2006). Leadership Competencies: Time to Change the Tune. Leadership, 2(2), 147-163, http://dx.doi. org/10.1177/1742715006062932

Boyatzis, R. E. (2008). Competencies in the 21st century. Journal of Management Development, 27(1), 5-12, http://dx.doi. org/10.1108/02621710810840730

Brooks, I. (2003). Systemic Exchange: Responsibility for Angst. Organisation Studies, 24(1), 125-141, http://dx.doi.org/10.11 77/0170840603024001682

Carroll, C., Booth, A., Papaioannou, D., Sutton, A. \& Wong, R. (2009). UK health-care professionals' experience of on-line learning techniques: A systematic review of qualitative data. Journal of Continuing Education in the Health Professions, 29(4), 235-241, http://dx.doi.org/10.1002/chp.20041

Cook, L. K., Cox, J. C., \& Henning, E. S. (2008). Breaking the Boundaries: Standardisation of a Competency Assessment Model for All Clinical Disciplines. Nurse Leader, 6(3), 34-40, http://dx.doi.org/10.1016/j.mnl.2008.04.002

Delamare Le Deist, F. \& Winterton, J. (2005). What Is Competence? Human Resource Development International, 8(1), 27-46, http://dx.doi.org/10.1080/1367886042000338227

Dimovski, V., Marič, M., Uhan, M., Đurica, N. \& Ferjan, M. (2012). Sun Tzu's "The Art of War" and Implications for Leadership: Theoretical Discussion. Organizacija, 45(4), 151-158, http://dx.doi.org/10.2478/v10051-012-0017-1

Engel, C. (2002). Common Assessment Framework: The state of affairs. Eipascope, 11(1), 35-39.

European Foundation for Quality Management (EFQM). (2013). The EFQM Excellence Model Fundamental Concepts. Retrieved 7 December 2013, from http://www2.efqm.org/en/ Home/TheEFQMExcellenceModel/FundamentalConcepts/ tabid/169/Default.aspx

European Institute of Public Administration (EIPA), Resource Centre. (2012). CAF 2013. Maastricht: European Institute of Public Administration.

Furukawa, P. d. O. \& Cunha, I. C. K. O. (2011). Profile and competencies of nurse managers at accredited hospitals. Revista Latino-Americana de Enfermagem, 19, 106-114, http://dx.doi.org/10.1590/S0104-11692011000100015

Institute of Public Health. (2010). Health Statistics Yearbook 2010. Ljubljana: Institute of Public Health of the Republic of Slovenia.

International Council of Nurses (2009). The role and identity of the regulator: an international comparative study. Geneva: International Council of Nurses.

Kvas, A. (2013). Leadership Competency Model in Health Care. Doctoral dissertation. Ljubljana: University of Ljubljana, Faculty of Administration.

Kvas, A. \& Seljak, J. (2013). Continuing Education and SelfAssessment of Knowledge of Nurse Leaders. The Journal of Continuing Education in Nursing, 44(8), 342-349, http:// dx.doi.org/10.3928/00220124-20130603-07 
Kvas, A., Seljak, J. \& Stare, J. (2013). The Use of Competency Models to Assess Leadership in Nursing. Iranian Journal of Public Health, 42(9), 988-995.

Lin, C.-J., Hsu, C.-H., Li, T.-C., Mathers, N., \& Huang Y.-C. (2010). Measuring professional competency of public health nurses: development of a scale and psychometric evaluation. Journal of Clinical Nursing, 19(21-22), 3161-3170, http:// dx.doi.org/10.1111/j.1365-2702.2009.03149.x

Lin, L.-M., Wu, J.-H. \& White, L. P. (2005). Managerial Activities and Skills of Nurse Managers: An Exploratory Study. Hospital Topics, 83(2), 2-9, http://dx.doi.org/10.3200/htps.83.2.2-9

Marulc, E. \& Devetak, G. (2013). The Impact of the Intellectual Charm of Physicians on the Healthcare Organisations. Organizacija, 46(1), 29-41, http://dx.doi.org/10.2478/orga2013-0004

McCarthy, G., \& Fitzpatrick, J. J. (2009). Development of a Competency Framework for Nurse Managers in Ireland. The Journal of Continuing Education in Nursing, 40(8), 346-350, http://dx.doi.org/10.3928/00220124-20090723-01

Muehlbacher, J., Kovač, J., Novotny, A. \& Putnová, A. (2013). Competency Management in Central Europe: A Comparison of Czech, Hungarian and Slovenian Competency Needs. Organizacija, 46(5), http://dx.doi.org/10.2478/orga-20130019

Munro, H. B. (2005). Statistical Methods for Health Care Research, Fifth edition. Philadelphia: Lippincott Williams \& Wilkins.

Northouse, G. P. (2007). Leadership - Theory and Practice. Thousand Oaks: Sage.

Organisation for Economic Co-operation and Development. (2001). Public sector leadership for the 21st century. Paris: OECD.

Rattray, J. \& Jones, M. C. (2007). Essential elements of questionnaire design and development. Journal of Clinical Nursing, 16(2), 234-243, http://dx.doi.org/10.1111/j.13652702.2006.01573.x

Sarkar, S. (2013). Competency based Training Need Assessment - Approach in Indian companies. Organizacija, 46(6), 253263, http://dx.doi.org/10.2478/orga-2013-0025

Spicer, J. G., Guo, Y., Liu, H., Hirsch, J., Zhao, H., Ma, W., et al. (2011). Importance of role competencies for Chinese directors of nursing based on the forces of magnetism. Journal of Nursing Management, 19(1), 153-159, http:// dx.doi.org/10.1111/j.1365-2834.2010.01182.x

Stare, J. (2009). Competency Models for Public Administration and Leadership Development. In M. Vintar \& P. Pevcin (Eds.), Contemporary Issues in Public Policy and Administrative Organisation in South East Europe (pp. 262-276). Ljubljana: University of Ljubljana, Faculty of Administration.

Stare, J. \& Seljak, J. (2013). Vodenje ljudi v upravi (2. ponatis) [Leadership in administration (2th edition)]. Ljubljana: University of Ljubljana, Faculty of Administration
Stefl, M. E. \& Bontempo, C. A. (2008). Common Competencies for All Healthcare Managers: The Healthcare Leadership Alliance Model. Journal of Healthcare Management, 53(6), 360-373.

Šparl, P., Žnidaršič, A., Kasper, H., Mühlbacher, J. \& Kovač, J. (2013). Management Competencies and Organisational Performance in CEE: A Comparison of Slovenia and Austria. Organizacija, 46(5), 214-220, http://dx.doi.org/10.2478/orga2013-0022

Twedell, M. D. \& Jackson Gray, J. (2007). Role Transition. In S. P. Yoder-Wise (Ed.), Leading and Managing in Nursing (pp. 515-529). St. Louis: Mosby - Elsevier.

World Health Organisation. (2013). Health expenditure ratios. Retrieved 10 December 2013, from http://apps.who.int/ ghodata/?vid=1901

Yoder-Wise, S. P., \& Brigher, A. S. (2007). Leading through professional associations. In S. P. Yoder-Wise (Ed.), Leading and managing in nursing (pp. 577-589). St. Louis: Mosby - Elsevier.

Andreja Kvas is a Senior Lecturer at the Faculty of Health Sciences, University of Ljubljana, Slovenia. She received her master's degree at the Faculty of Social Science and doctorate at the Faculty of Administration, University of Ljubljana. She is a vice-president of the Nurse and Midwifery Organisation of Ljubljana, responsible for the field of education, research and publishing. Her research interests include health care, education, public sector and leadership.

Janko Seljak is an Independent Researcher at the Faculty of Administration, University of Ljubljana, Slovenia. He received his master's degree and doctorate at the Faculty of Economics, University of Ljubljana. His research focuses on statistics, data envelopment analysis (DEA), performance indicators, public sector and health care.

Janez Stare is an Assistant Professor of Public Sector Organisation at the Faculty of Administration, University of Ljubljana, Slovenia. He holds a master's degree in HRM and a doctorate in leadership in public administration. His main research interests are current issues in human resources management, leadership and public sector organisation. He participates as a head or a member in a variety of projects (Innovative solutions for a better work environment, Leadership competence model for public administration). He is a member of The Officials Council of the Republic of Slovenia and a member of professional bodies of the Slovenian Association for Human Resource Management and Industrial Relations. 